\title{
Association between experience of sexual coercion and sexual behaviour: insights from the 2008 Botswana AIDS impact survey III
}

\author{
Gobopamang Letamo \\ Department of Population Studies, University of Botswana \\ Private Bag UB 00705, Gaborone, Botswana \\ Tel: (267) 355-4167; Fax: (267) 318-5099 \\ Email: letamog@mopipi.ub.bw or gobopamang@yahoo.co.uk
}

\begin{abstract}
Objective: Little is known about the prevalence and the effect of sexual coercion on risky sexual behaviour in the context of Botswana. The aim of this study was to investigate the association between the experience of sexual coercion and risky sexual behaviour.
\end{abstract}

Methods: The study used a nationally representative population-based survey data from the 2008 Botswana AIDS Impact Survey III. We used cross-tabulations and multivariate logistic regression analysis to investigate an association between the experience of sexual coercion and risky sexual behaviour.

Results: Out of the 2,455 respondents, the prevalence of sexual coercion was $5 \%(3.1 \%$ males and $8.1 \%$ females). The adjusted odds ratios showed that only the respondents who reported having experienced sexual coercion compared to those who did not were 1.9 times more likely to report having engaged in multiple sexual partnerships and this relationship was statistically significant at $1 \%$ level.

Conclusion: The results suggest that in order to implement effective HIV/AIDS prevention strategies it is imperative to adopt a more holistic and multifaceted approach that includes issues of sexual violence.

Keywords: Sexual coercion; sexual behaviour; Botswana

\section{Résumé}

Objectif: On connaît la prévalence et l'incidence de la coercition sexuelle sur les comportements sexuels à risque dans le contexte du Botswana. Cette étude visait à examiner le lien entre l'expérience de la coercition sexuelle et les comportements sexuels à risque.

Méthodes: L'étude a utilisé une données représentatives au niveau national axée sur la population de la 2008 Botswana AIDS Impact Survey III. Nous avons utilisé des croisés et l'analyse de régression logistique multivariée pour enquêter sur une association entre l'expérience de la coercition sexuelle et les comportements sexuels à risque.

Résultats: Sur les 2455 répondants, la prévalence de la coercition sexuelle était de 5 \% (3,I \% hommes et $8,1 \%$ des femmes). Les rapports de cotes ajustés ont montré que seulement les répondants qui déclarent avoir subi la coercition sexuelle par rapport à ceux qui n'ont pas étaient $I, 9$ fois plus susceptibles de déclarer avoir entrepris des partenariats sexuels multiples et cette relation était statistiquement significative au niveau de $\mathrm{l} \%$.

Conclusion: Les résultats suggèrent que pour mettre en œuvre des stratégies efficaces de prévention du $\mathrm{VIH} /$ sida il est impératif d'adopter une approche plus holistique et aux multiples facettes qui comprend des questions de violence sexuelle.

Mots clés: Sexuelle contrainte ; comportement sexuel ; Botswana

\section{Introduction}

Previous studies have demonstrated that the experience of sexual coercion leads to a greater likelihood of risky sexual behaviour, such as having multiple sexual partners and inconsistent or non-use of condoms (Biglan, et. al., 1995; Koeng et. al., 2004; Agardh, Odberg-Pettersson and Ostergren, 201I).
Because most HIV/AIDS prevention intervention programmes target these behaviours, knowledge of the experience of sexual coercion and its subsequent impact on risky sexual behaviours is vitally important especially in a country like Botswana where HIV prevalence is high. 
Sexual violence is a global public health problem. Globally, one in four women experience sexual violence by an intimate partner (Hakimi 200I; Ellsberg, 1997). A study in South Africa reported that $10 \%$ of $15-19$ year old women were forced to have sex against their will by their current or ex-partners (Department of Health et.al, 2002). A study conducted in central Baganda region of Uganda found that $22 \%$ of women reported that they had been forced to have sex against their will at some point in their adult lives (Okongo, 1991: cited in Heise, Moore and Toubia, 1995). Another study in Egypt found that of the 160 Egyptian girls and women revealed that sexual aggression by adult men toward young girls occurred in $45 \%$ of low socioeconomic status (SES) families and $34 \%$ of high SES families (deChesney, 1989). A study in Lebanon found that $26.2 \%$ of women reported experiencing forced sexual intercourse in the past year (Khawaja and Hammoury, 2008).

Available literature suggests that sexual coercion increases risky sexual behaviour. For example, Republic of Botswana \& UNDP (2000) stated that "coercive sex, including rape, facilitates the transmission of HIV, and is especially efficient in doing so when the violations are against young women and the girl child, amongst whom the risk of extensive damage to genital mucosa is high" (p.29). Previous researches demonstrate significant associations between spousal sexual violence and risky sexual behaviour among women. For instance, women who experienced sexual violence were less likely to use condoms during intercourse because they were forced (Kiragu and Zabin, 1993; Koeng et. al, 2003). Other studies have found that such women are more likely to have multiple sexual partners (Heise et. al., 1993; Olsson et al., 2000).

Sexual coercion is also associated with compromised health outcomes such as unwanted pregnancy, sexually transmitted diseases, fear of sex, inability to use condoms, and abortion-related injury (Heise, Moore and Toubia, 1995). A study in rural South Africa found that sexual coercion within intimate relationships increased the likelihood of engaging in unprotected sex (Hoffman et al, 2006). Ohene et al (2005) stated that sexual abuse is associated with health-compromising behaviours which may include drug and alcohol use, multiple sexual partners, and engaging in unprotected sex.

One of the factors identified as a key driver of the HIV/AIDS epidemic in Botswana is gender-based violence (Maundeni, 200I). The Botswana Millennium Development Status Report reports that violence against women is one of Botswana's biggest gender issues (Republic of Botswana \& United Nations, 2010). The report acknowledges that the magnitude of violence against women is difficult to ascertain because of the problem of underreporting. This underreporting of violence is said to stem from various factors, including the victim's economic dependence on the abuser, stigma, family pressure, and the quality of institutional support (Republic of Botswana \& United Nations, 20I0). In recognizing that sexual violence is a problem in the country, Botswana government passed a Domestic Violence Act of 2008 with the objective of protecting those abused in their own homes (Republic of Botswana, 20I2).

Despite the increasing recognition of the significance of sexual coercion in developing countries, evidence on its consequences for reproductive health remains limited (Wandera, Ntozi and Kwagala, 2010). Although sexual aggression has been theorized to be an important factor in the spread of HIV and AIDS worldwide, little empirical research exists on the topic (Amaro, Raj \& Reed, 200I; Doll \& Carballo-Dieguez, 1998; Martin \& Curtis, 2004: cited in Peterson 2010), especially in Botswana. Peterson (20I0) argues that more research is needed on the associations between STI/HIV risk and sexual aggression. WHO (2002) also explicitly argue that although violence against women is a fact of life for many women, the true extent of this violence is unknown. Therefore the purpose of this study is to examine the association between sexual coercion and sexual behaviour in Botswana.

\section{Data and methods}

\section{Data source}

The current study uses secondary data derived from the 2008 Botswana AIDS Impact Survey III, which is a nationally representative population-based survey whose main objective was to provide up to date information of the HIV and AIDS pandemic in Botswana with respect to its prevalence, incidence as well as behavioural patterns and knowledge, care and support, attitude toward PLWHA, as well as socioeconomic, demographic and household and living conditions associated with the disease (Republic of Botswana, 2009). In this survey, unlike the previous ones, blood samples were collected from willing respondents for the determination of HIV prevalence and incidence. Using stratified two stage sample design a sample of 8275 households was drawn systematically from a listing of households within selected EAs prepared at the beginning of fieldwork. The response rate was $82 \%$ (Republic of Botswana, 2009).

\section{Study Sample}

The sample used for the purpose of this study comprised of all individuals who have fully completed the individual questionnaire, were aged 15-64 years, 
and have ever had sexual intercourse. The sample size depends on the outcome variable of interest. For instance, there were 2,09I respondents regarding condom use during the last sexual intercourse and 2,139 respondents regarding the number of sexual partners.

\section{Measurement of variables \\ Independent variable}

The key independent variable in this study is the experience of sexual coercion. The concept of sexual coercion can be defined differently by different scholars. But for the purpose of this study, experience of sexual coercion was measured based on a question, "Have you ever had sex without your consent?" and the responses were "yes" and "no". A response of "yes" was treated to mean that the respondent had experienced sexual coercion. It should be noted that this question was asked of respondents who reported ever having had sexual intercourse.

\section{Sexual behaviour variables}

Since the purpose of this study was to investigate the association between the experience of sexual coercion and risky sexual behaviour, we needed to identify what variables will be used to study sexual behaviour and these variables are discussed below.

Having multiple sexual partners

Having multiple sexual partners was measured by asking the respondents the following question: "In the last 12 months, with how many people overall have you had sexual intercourse (including the last partners we've discussed)?" The variable was dichotomized so that $\geq 2$ was coded as "multiple sexual partners" and 0 or I as "one sexual partner or none".

Condom use at the last sexual intercourse

This variable was derived from a question: "The last time you had sexual intercourse with this partner did you or this partner use a condom?" The responses were coded so that "yes, male condom" and "yes, female condom" formed "yes" category and "no" category comprised of the following responses: "no" and "don't remember".

\section{Statistical analysis}

The statistical analyses were conducted using SPSS Version 19.0. Sample characteristics were calculated using frequencies and cross-tabulations. Multivariate logistic regression analysis was performed to investigate the association between sexual coercion and risky sexual behaviour and was adjusted for age, marital status, education, place of residence, and religious affiliation.

\section{Results \\ Description of the Sample}

Out of the 2,455 respondents, about $62 \%$ were males and $38 \%$ females. Approximately two-thirds of the sexually experienced respondents were 20-29 years old and about $15 \%$ were aged $15-19$ years (see Table I). About $77 \%$ of the respondents were unmarried and $22.3 \%$ were either currently married or living with their partner.

With regard to education, more than $80 \%$ had at least secondary education while only $5.5 \%$ had no education at all, the majority of them males. About $65 \%$ of the respondents were Christians while $31 \%$ had no religious affiliation. Respondents were evenly distributed between cities/towns, urban villages and rural villages, roughly a third in each location.

About one in twenty respondents reported having had sexual intercourse before the age of 15 years and most of these respondents were predominantly males. Twenty-five percent of sexually experienced respondents reported having had sexual intercourse with at least two partners in the last 12 months. Most of the respondents who reported having had multiple sexual partnerships in the past 12 months were males. Only fifteen percent of the respondents reported that they did not use condoms during their last sexual intercourse and most of the respondents who reported non-use of condoms were females. One in twenty respondents reported to have ever experienced sexual coercion and the majority of respondents who have experienced sexual coercion were females.

\section{Relationship between sexual coercion and sexual behaviour}

Overall, the prevalence of sexual coercion was reported to be one in twenty sexually experienced respondents. Table 2, 3 and 4 show the impact of sexual coercion on the three risky sexual behaviours studied, namely, non-use of condom and having multiple sexual partnerships, respectively.

Relationship between sexual coercion and non-use of condom

Table 2 presents the result of multivariate logistic regression analysis using two models, Model I showing unadjusted odds ratio and Model II showing adjusted odds ratios. Model I results indicated that respondents who have ever experienced sexual coercion were 1.7 times more likely not to have used a condom during their last sexual intercourse compared with those who had never experienced sexual coercion and this relationship was statistically significant at $5 \%$ level. If controls are introduced, respondents who have ever experienced sexual coercion were 1.4 times more likely not to have used a condom during their last sexual intercourse 
compared with those who had never experienced sexual coercion and this relationship was not statistically significant.

Respondents older than 20 years were more likely not to have used a condom during their last sexual intercourse compared with those who were aged less than 20 years and these relationships were statistically significant at $5 \%$ level. For instance, respondents aged 30-39 years were 4 times more likely not to have used a condom during their last sexual intercourse compared with those who were aged less than 20 years.

Females were 2.3 times more likely not to have used a condom during their last sexual intercourse compared with their male counterparts. Respondents with no or low level of education were more likely not to have used a condom during their last sexual intercourse compared with those who had postsecondary education and these relationships were statistically significant at $5 \%$ level. For example, respondents with no education were 6 times more likely not to have used a condom during their last sexual intercourse compared with those who had post-secondary education. Respondents who were ever married were 3 times more likely not to have used a condom during their last sexual intercourse compared with those who were never married and this relationship was statistically significant at $5 \%$ level.

Relationship between sexual coercion and multiple sexual partnerships

Table 3 shows the results of logistic regression analysis with both unadjusted and adjusted odds ratio models. Model I showed that although not statistically significant, respondents who have ever experienced sexual coercion were I.4 times more likely to have had sexual intercourse with more than one sexual partner in the past 12 months compared with those who have never experienced sexual coercion. Once controls were introduced (Model II), respondents who have ever experienced sexual coercion were 1.9 times more likely to have had sexual intercourse with more than one sexual partner in the past 12 months compared with those who have never experienced sexual coercion and this relationship was statistically significant at $5 \%$ level.

Respondents who were aged 20-29 years were I.4 times more likely to have had sexual intercourse with more than one partner in the last 12 months compared with those aged less than 20 years old. Females were less likely to report having had sexual intercourse with more than one partner in the last 12 months compared with their male counterparts and this relationship was statistically significant at $5 \%$ level. Other variables did not appear to be related to having had sexual intercourse with more than one sexual partner in the past 12 months.

\section{Discussion and conclusions}

The purpose of this study was to examine the association between sexual coercion and sexual behaviour in Botswana. To effectively deal with HIV issues, understanding the interrelationships between different factors is very important. The current study provides insights into how the experience of sexual coercion impacts on sexual behaviour. One of the key findings of the study is that sexual coercion was reported by one in twenty respondents, the majority of whom were women. As noted early in the literature, the estimated prevalence could be an underestimate because of various reasons such as the victim's economic dependence on the abuser, stigma, family pressure and the quality of institutional support (Republic of Botswana and United Nations, 2010). The higher proportions of women reporting having experienced sexual coercion also emphasizes the finding that violence against women is one of the biggest gender issues in Botswana (Women's Affairs department, 1999; Republic of Botswana and United Nations, 2010). More often than not, the perpetrators of violence against women are men (husbands, boyfriends and male family members (Maundeni, 200I).

Male sexual coercion in Botswana has not been studied in-depth. Little is known about sexual coercion among males as victims. Population Council (2004) observed that young men, like women, report experiencing a variety of coercive behaviours, ranging from unwanted touch, verbal abuse, unwanted kiss and deception that sets the stage for coercion to the use of violent force. The available literature concludes that for the most part, perpetrators of violence on young male victims are males and are known persons not strangers (Population Council, 2004). The literature also noted that a smaller number of young men reported sexual coercion by females (Population Council, 2004). On the basis of this evidence it is highly likely that the small proportion of men who reported experiencing sexual coercion in this study could have been coerced by their peers or older men rather than females. Incidents of sexual coercion in the country are often reported by male prison inmates.

Respondents who reported having experienced sexual coercion compared to those who did not were more likely not to have used condoms during the last sexual intercourse and this relationship was statistically significant at $5 \%$ level. After introducing controls, this relationship disappears, implying that assuming the respondents had similar distribution in terms of sex, age, marital status, educational level, religious affiliation and place of residence, having experienced sexual coercion does not influence nonuse of condom at last sexual intercourse. Thus the 
statistical significance of the relationship between sexual coercion and non-use of condom could also be explained by any of these other confounding variable. As such the initial relationship observed between sexual coercion and non-use of condom at last sexual intercourse was completely due to the confounding variables and not because of sexual coercion. This finding is consistent with the findings by Bauer et al. (200I).

The relationship between the experience of sexual coercion and engaging in multiple sexual partnerships was not statistically significant. However, the introduction of controls in the model led to a strong statistically significant relationship between reported sexual coercion and engagement in multiple sexual partnerships. Thus people who reported having ever experienced sexual coercion were 1.9 times more likely to report having multiple sexual partners than those who reported no experience of sexual coercion. However, females were less likely to report any engagements in multiple sexual partnerships. This finding is consistent with previous results where it was evident that more males compared to females were engaged in multiple sexual partnerships (Letamo and Mokgatlhe, 2013). The results imply that when the confounding variables are not held constant (age, sex, marital status, education, religion and residence) one may wrongly conclude that there is no statistically significant relationship between sexual coercion and multiple sexual partnerships when in fact there is.

Although these factors were introduced as controls, it is worth noting that being older, being female, being ever married and having no or low educational attainment were associated with an increased likelihood of not having used a condom at the last sexual encounter.

The relationship between sexual coercion and early sexual debut was not statistically significant. However, older people were less likely to report that having started their first sexual experience before the age of 15 years. The delayed age at first sexual intercourse among the older cohorts could be suggestive of the traditional controls which were enforced at the time to ensure that sexual intercourse took place in only sanctioned institutions such as marriage. Females were less likely to have reported having had their first sexual intercourse before the age of 15 years compared with their male counterparts.

\section{Conclusion}

This study demonstrated existence of sexual coercion among sampled men and women in Botswana. Since one-in-twenty respondents reported to have experienced sexual coercion, especially women, addressing the problem of sexual coercion which has considerable impact in preventing HIV infection is important. The study results showed that there is no statistically significant relationship between sexual coercion and non-use of condom at the last sexual intercourse when one holds potential confounders constant. However, sexual coercion is statistically related to engagement in multiple sexual partnerships when confounders have been controlled for. Appropriate policies and programmes need to be formulated to address the prevalence of sexual coercion which tends to fuel the spread of HIV infection in the country. If not adequately addressed, the Botswana Vision Goal of no new HIV infections by 2016 would be in vain. Thus a much more holistic approach to HIV prevention is needed if HIV is to be stemmed out.

\section{Study Limitations}

The major limitation of this study was that secondary data were used, thereby limiting the researcher to variables collected by the survey. For instance, in order to argue that there is a causal relationship between experience of sexual coercion and risky sexual behaviour, the experience of sexual coercion must have taken place before the risky sexual behaviour occurs. Otherwise, the lack of sequencing of these events creates difficulty in arguing for causal relationships. Therefore these cross-sectional data limit conclusion to correlations rather than cause and effect relationships.

Another limitation of the study was that the information collected was self-reported, which was subject to reporting errors and biases. The data are subject to reporting errors and biases in that some respondents may report what they think the interviewer wants to hear rather than their actual experience.

The third limitation was that since the questions ask about sexual coercion which respondents might not be comfortable talking about and this discomfort could lead to underreporting of levels of sexual coercion. Some respondents may feel embarrassed to talk about their experience of sexual coercion for fear of being judged and possibly discriminated against because of their experience. Therefore, some respondents may simply report that they have never experienced sexual coercion, leading to the underestimation of the event.

\section{References}

Agardh $\mathrm{A}$, Odberg-Pettersson $\mathrm{K}$, and Ostergren $\mathrm{P}$ (20II). Experience of sexual coercion and risky sexual behaviour among Ugandan university students. BMC Public Health, I I:527

Amaro H, Raj A, Reed F. (200I). Women's sexual health: The need for feminist 
analysis in the public health in the decade of behaviour. Psychology of Women Quarterly. 25: 324-334.

Bauer HM; Gibson P; Hernandez M; Kent C; Klausner J; and Bolan G. (200I). Intimate

Partner Violence and High-Risk Sexual Behaviors Among Female Patients with Sexually Transmitted Diseases. American Sexually Transmitted Diseases Association. 29(7): 4I I-4l6.

Biglan A, Noell J, Ochs L, Smolkowski K, Metzler C (1995) Does sexual coercion play a role in the high-risk sexual behaviour of adolescent and young adult women? Journal of Behavioural Medicine, I8(6): 549-568.

deChesney M (1989). Child Sexual Abuse as an International Health Problem,

International Nurses Review, 36(5): 149-153.

Department of Health, Medical Research Council and Measure DHS+ (1998). South

Africa Demographic and Health Survey. Full Report. Pretoria, Department of Health.

Doll LS, Carballo-Dieguez A (1998). Physical and sexual coercion and HIV risk:

Editorial, AIDS and Behavior, 2: 31-32.

Ellsberg MC (1997). Candies in Hell: Domestic Violence against Women in

Nicaragua, Umea, Umea University.

Go VF, Srikrishnan AK, Salter ML, Mehta S, Johnson SC, Sivaram S, Davis W, Solomon S, Celentano DD (2010). Factors associated with the penetration of sexual violence among wineshop patrons in Chennai, India. Social Science \& Medicine, 1277-I 284.

Hakimi M (200I). Silence for the sake of harmony: Domestic violence and women's health in central Java, Yogyakarta, Gadjah Mada University.

Heise L (1993) Violence against women: the hidden health burden, World Health Stat Q, 46(I): 78-85.

Heise L, Moore K, Toubia N (1995). Sexual Coercion and Reproductive Health, New York, Population Council.

Hoffman S, O'Sullivan LF, Harrison A, Dolezal C, Monroe-Wise A (2006). HIV Risk Behaviors and the Context of Sexual Coercion in Young Adults' Sexual Interactions: Results From a Diary Study in Rural South Africa, Sexually Transmitted Diseases, 33(I): 52-58.

Khawaja M, Hammoury N (2008). Coerced Sexual Intercourse Within Marriage: A

Clinic-Based Study of Pregnant Palestinian Refugees in Lebanon, Journal of Midwifery \& Women's Health, 53(2): I50-I54.

Kiragu K and Zabin L (1995). Contraceptive use among high school students in
Kenya, International Family Planning Studies, 2 I (3): I08-II3.

Koenig MA, Lutalo T., Zhao F, Nalugoda F, WabwireMangen F, Kiwanuka N, Wagman J, Serwadda D, Wawer M, Gray R (2003). Domestic violence in rural Uganda: evidence from a communitybased study. Bulletin of the World Health Organization: 8I(I): 53-60.

Koenig MA, Zablotska I, Lutalo T, Nalugoda F, Wagman J, Gray R (2004). Coerced

first intercourse and reproductive health among adolescent women in Rakai, Uganda, International Family Planning Perspectives, 30(4): I56-163.

Letamo G, and Mokgatlhe LL (2013). Predictors of risky sexual behaviour among young people in the era of HIV/AIDS: evidence from the 2008 Botswana AIDS Impact Survey III. African Journal of Reproductive Health. 17(3): 169181.

Martin SL, Curtis S (2004). Gender-based violence and HIV/AIDS: Recognizing links

and acting on evidence, Lancet, 363, 1410I4II.

Maundeni T (200I). Gender Based Violence Against Women and Children and HIV/ AIDS, Report of the First National Conference on Gender and HIV/AIDS Gaborone, Ministry of Labour and Home Affairs, 73-84.

Ohene S, Halcon L, Ireland M, Carr P, McNeely C (2005). Sexual Abuse History, Risk Behavior, and Sexually Transmitted Diseases: The Impact of Age at Abuse, Sexually Transmitted Diseases, 32(6): 358-363.

Olsson A, Ellsberg M, Berglund S, Herrera A, Zelaya E, Pena R (2000). Sexual abuse during childhood and adolescence among Nicaraguan men and women: A

population-based anonymous survey. Child Abuse and Neglect, 24: I579-I589.

Peterson ZD, Jansen E, Heiman JR (20I0). The Association Between Sexual

Aggression and HIV Risk Behaviour in Heterosexual Men. Journal of Interpersonal Violence. 25(3): 538-556.

Population Council (2004). Sexual Coercion: Young Men's Experiences as Victims

and Perpetrators, Population Council, New York.

Republic of Botswana and United Nations Development Programme (2000). Botswana Human Development Report - Towards an AIDS-Free Generation, 2000. Gaborone, Editorial Services.

Republic of Botswana (2009). Preliminary Botswana HIV/AIDS Impact Survey Results. Stats Brief, May. NACA and CSO Republic of Botswana and 
United Nations (2010). Botswana Millennium Development Goals Status Report 2010, Gaborone, Ministry of Finance \& Development Planning.

Republic of Botswana and United Nations (20/2).

Report Presented During the $56^{\text {th }}$

Session of the United Nations Commission on the Status of Women, $29^{\text {th }}$ February, New York, United States of America.

Seto MC, Kjeligren C, Priebe G, Mossige S, Svedin CG, Langstrom N (20I0). Sexual

Coercion Experience and Sexually Coercive Behaviour: A Population Study of Swedish and Norwegian Male Youth. Child Maltreatment, I5(3): 219-228.

Stephenson R, Koenig MA, Ahmed S (2006). Domestic Violence and Symptoms of
Gynecologic Morbidity Among Women in North India, International Family Planning Perspectives, 32(4): 20I-2I2.

Wandera SO, Ntozi JPM, Kwagala B (2010). Spousal sexual violence, sexual

behaviour and sexually transmitted infections among ever-married women in Uganda, African Population Studies, 24(I\&2): 7087.

Women's Affairs Department (1999). Report on the Study on the Socio-economic

Implications of Violence Against Women in Botswana, Gaborone, Ministry of Labour and Home Affairs.

WHO (2002). World Report on Violence and Health. Geneva, Switzerland. 
Table I: Percentage distribution of respondents categorized by socio-demographic characteristics, 2008 BAIS III

\begin{tabular}{|c|c|c|c|c|c|c|}
\hline \multirow{2}{*}{ Characteristic } & \multicolumn{2}{|l|}{ All } & \multicolumn{2}{|l|}{ Male } & \multicolumn{2}{|c|}{ Female } \\
\hline & $\mathrm{n}$ & $\%$ & $\mathrm{n}$ & $\%$ & $\mathrm{n}$ & $\%$ \\
\hline \multicolumn{7}{|l|}{ Age } \\
\hline$<20$ & 367 & 14.9 & 157 & 10.4 & 210 & 22.4 \\
\hline $20-29$ & 1611 & 65.9 & 1021 & 67.3 & 590 & 62.8 \\
\hline $30-39$ & 376 & 15.3 & 268 & 17.7 & 108 & 11.5 \\
\hline $40-49$ & 101 & 4.1 & 70 & 4.6 & 31 & 3.3 \\
\hline \multicolumn{7}{|l|}{ Marital status } \\
\hline Never married & 1917 & 76.7 & 1221 & 79.1 & 696 & 72.9 \\
\hline Ever married & 581 & 23.3 & 322 & 20.9 & 259 & 27.1 \\
\hline \multicolumn{7}{|l|}{ Education } \\
\hline None & 137 & 5.5 & 113 & 7.3 & 24 & 2.5 \\
\hline Primary & 304 & 12.2 & 227 & 14.7 & 77 & 8.1 \\
\hline Secondary & 1434 & 57.4 & 861 & 55.9 & 573 & 59.9 \\
\hline Higher & 622 & 24.9 & 340 & 22.1 & 282 & 29.5 \\
\hline \multicolumn{7}{|l|}{ Religion } \\
\hline Christian & 1614 & 64.7 & 857 & 55.7 & 757 & 79.3 \\
\hline Other & 117 & 4.7 & 96 & 6.2 & 21 & 2.2 \\
\hline No religion & 763 & 30.6 & 586 & 38.1 & 177 & 18.5 \\
\hline \multicolumn{7}{|l|}{ Residence } \\
\hline Cities/towns & 842 & 33.7 & 512 & 33.2 & 330 & 34.5 \\
\hline Urban Villages & 839 & 33.5 & 490 & 31.7 & 349 & 36.5 \\
\hline Rural Villages & 820 & 32.8 & 542 & 35.1 & 278 & 29.0 \\
\hline \multicolumn{7}{|l|}{ Age at sexual debut } \\
\hline$<15$ & 121 & 4.8 & 108 & 7.0 & 13 & $\mathrm{I} .4$ \\
\hline$\geq 15$ & 2374 & 95.2 & 1409 & 93.0 & 1939 & 98.6 \\
\hline \multicolumn{7}{|l|}{ Number of sexual partners in past year } \\
\hline 0 or 1 & 1614 & 75.5 & 894 & 69.5 & 720 & 84.4 \\
\hline$\geq 2$ & 525 & 24.5 & 392 & 30.5 & 133 & 15.6 \\
\hline \multicolumn{7}{|l|}{ Condom use at the last sexual intercourse } \\
\hline Condom used & 1784 & 85.3 & 1104 & 87.8 & 680 & 81.5 \\
\hline Condom not used & 307 & 14.7 & 153 & 12.2 & 154 & 18.5 \\
\hline Experience of sexual coercion & & & & & & \\
\hline Yes & 124 & 5.0 & 47 & 3.1 & 77 & 8.1 \\
\hline No & 2361 & 95.0 & 1489 & 96.9 & 872 & 91.9 \\
\hline Total & 2455 & 100.0 & 1516 & 61.8 & 939 & 38.2 \\
\hline
\end{tabular}


Table 2: Association between experienced sexual coercion and non-use of condom at the last sexual intercourse, 2008 BAIS III (Expressed as Odds Ratios, 95\% Confidence Intervals)

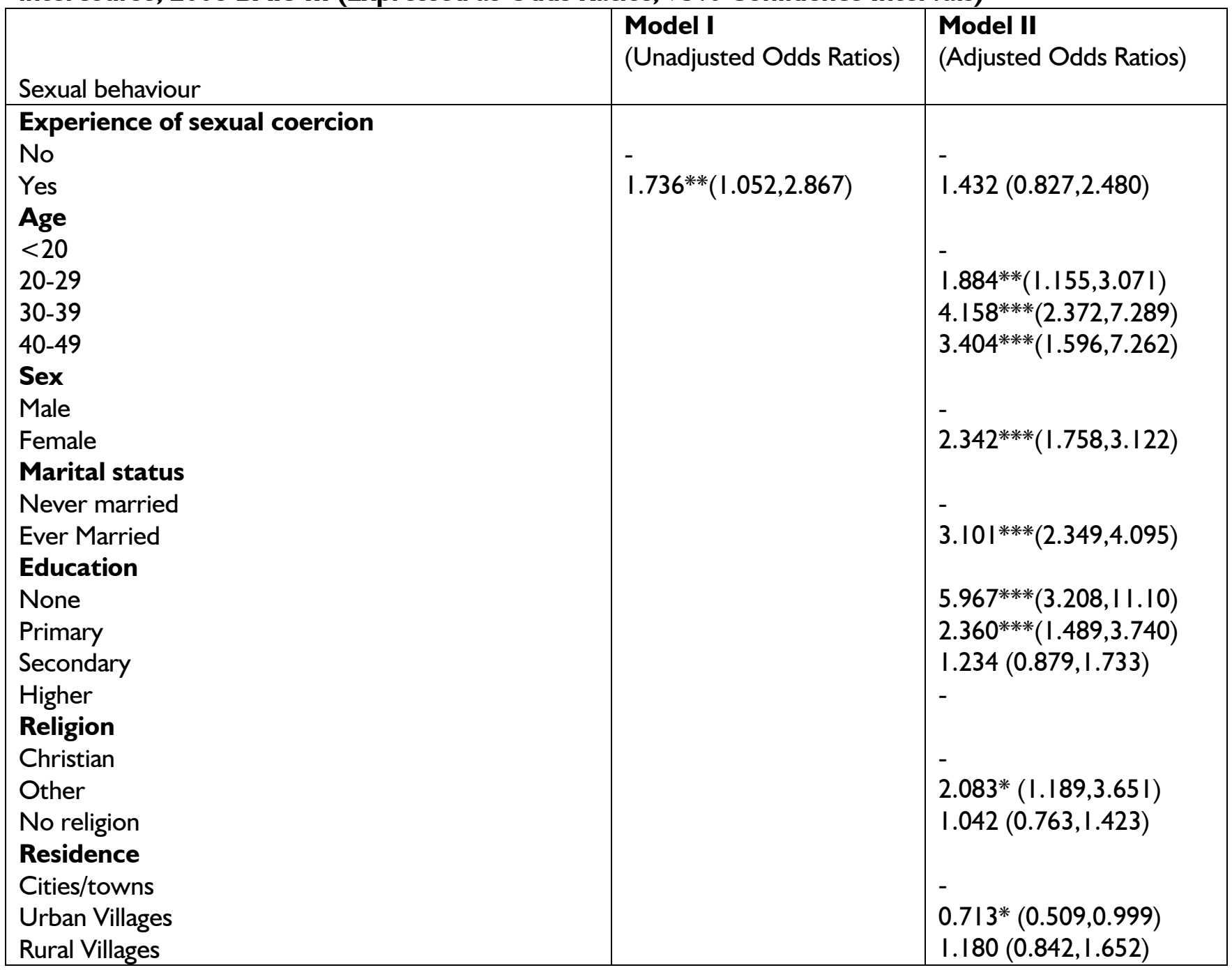

Notes: Significant at ${ }^{* * *} \mathrm{p}<0.01 ;{ }^{* *} \mathrm{p}<0.05 ;{ }^{*} \mathrm{p}<0.10$ 
Table 3: Association between experienced sexual coercion and multiple sexual partnerships, 2008 BAIS III (Expressed as Odds Ratios, 95\% Confidence Intervals)

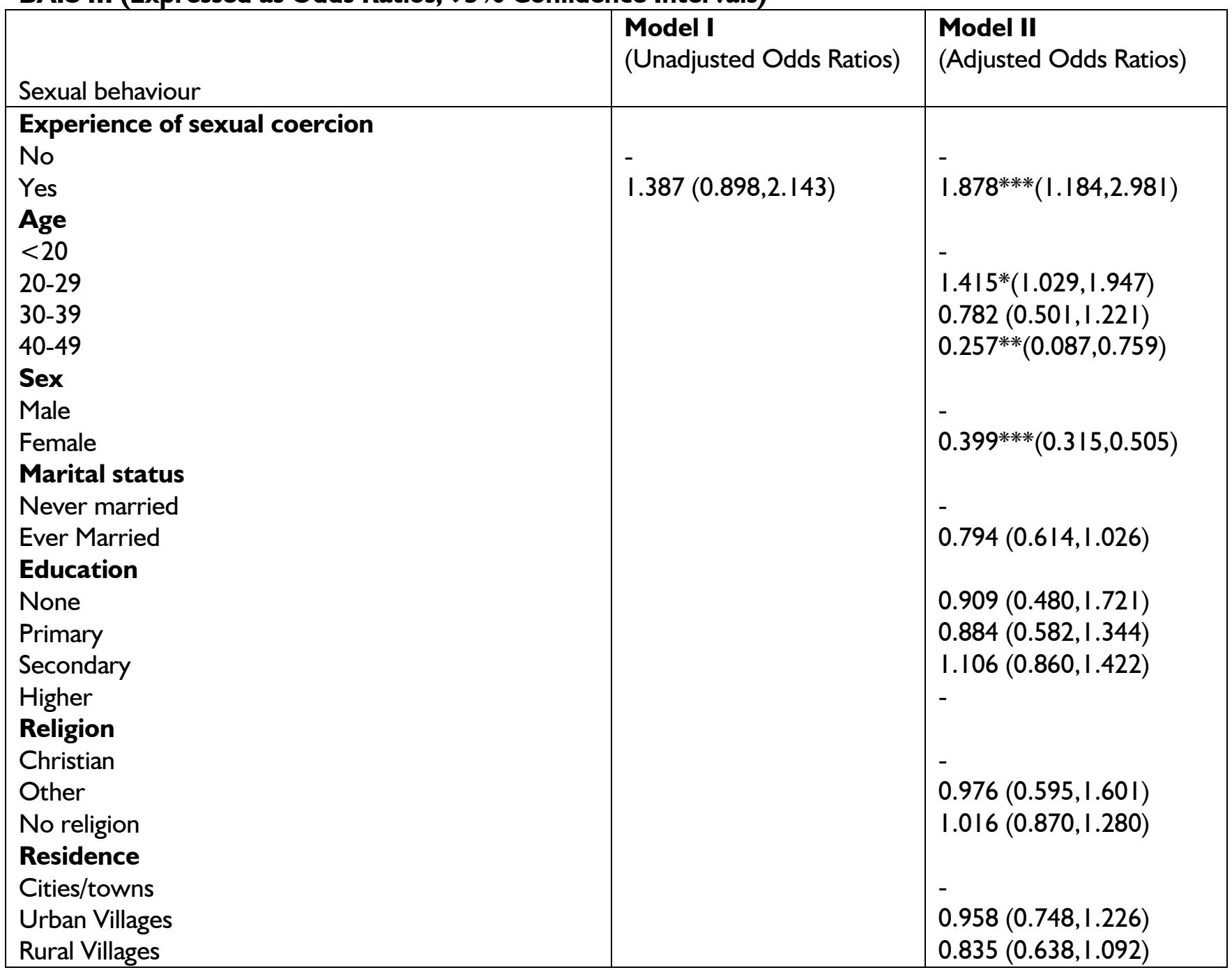

Notes: Significant at ${ }^{* * *} \mathrm{p}<0.01 ; *^{*} \mathrm{p}<0.05 ;{ }^{*} \mathrm{p}<0.10$ 